\title{
The Modern Surgical Strategy for Endometrial Cancer: Laparoscopic Surgery
}

\author{
Joo-Hyun Nam • Jeong-Yeol Park
}

Published online: 7 December 2012

(C) Springer Science+Business Media New York 2012

\begin{abstract}
Surgical staging and management through laparotomy has been the "gold standard" for treatment of endometrial cancer. However, recent advances in laparoscopic surgical techniques and instrumentation have meant that all surgical procedures for the treatment of endometrial cancer can now be performed using laparoscopy, which has naturally led to an increase in its use for treating this condition. Indeed, laparoscopic surgery is now the preferred alternative to laparotomy for the surgical management of endometrial cancer. Laparoscopic surgery is associated with improved outcomes, less complications, and improved quality of life, without compromising survival of patients. This review provides an update on the role of laparoscopic surgery for the surgical management of endometrial cancer with particular emphasis on feasibility, safety, and efficacy, based on the results of randomized, controlled trials comparing laparoscopy and laparotomy for surgical staging of endometrial cancer.
\end{abstract}

Keywords Endometrial cancer · Laparoscopy ·

Laparotomy $\cdot$ Staging operation $\cdot$ Surgical management

\section{Introduction}

Endometrial cancer is the sixth most common female cancer and the second most common gynecologic cancer worldwide $[1,2]$. It is the most common gynecologic cancer in developed western countries [3, 4], and the number of patients in these countries is increasing [5]. In eastern countries, the incidence also is increasing rapidly [5], and

\footnotetext{
J.-H. Nam $(\varangle) \cdot$ J.-Y. Park

Department of Obstetrics and Gynecology, University of Ulsan

College of Medicine, Asan Medical Center,

\#388-1, Poong-nap Dong, Song-pa Gu,

Seoul 138-736, South Korea

e-mail: jhnam@amc.seoul.kr
}

it will likely become the most common gynecologic cancer in the near future [6-9].

Approximately $75 \%$ of endometrial cancers are diagnosed at an early stage in which the disease is confined to the uterus [10]. The cure and survival rate is very high in these patients after surgical management, with or without adjuvant therapy. Surgical management is the mainstay of treatment for patients with endometrial cancer. Contemporary standard surgical management for endometrial cancer includes total hysterectomy, bilateral salpingo-oophorectomy, and pelvic and/or paraaortic lymphadenectomy through laparotomy. However, a recent trend in the surgical management of endometrial cancer is the use of laparoscopic surgery. Laparoscopic surgery has been shown to have several benefits over a conventional abdominal approach in the surgical management of benign disease, including less postoperative pain, improved cosmesis, less blood loss, shorter recovery time, and shorter length of hospital stay without increasing perioperative complications [11]. Indeed, whilst endometrial cancer is the first gynecologic cancer to be treated laparoscopically, a laparoscopic approach also is being used for the surgical management of malignant disease. Following the first report on the use of laparoscopic surgery for endometrial cancer by Childers et al. [12], the feasibility, safety, and efficacy of laparoscopic surgery in the surgical management of endometrial cancer has been reported in numerous retrospective studies [13-25], prospective nonrandomized studies [26-29], or randomized, controlled trials

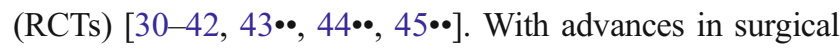
technique and instrumentation, laparoscopic surgery recently has become widely used for the surgical management of endometrial cancer, with an increasing role being noted for treatment of the disease.

This review provides an update on the role of laparoscopic surgery for the surgical management of endometrial cancer with particular emphasis on feasibility, safety, and efficacy based on the results of randomized, controlled trials 
comparing laparoscopy and laparotomy for surgical staging of endometrial cancer.

\section{Feasibility of Laparoscopic Surgery}

With recent advances in surgical instrumentation and technique, all surgical procedures for the management of endometrial cancer can now be performed using laparoscopy. However, in the largest randomized, controlled trial (Gynecologic Oncology Group (GOG), LAP 2 trial) comparing laparoscopy with laparotomy for surgical staging of endometrial cancer, the rate of conversion to laparotomy after initially being assigned to laparoscopic surgery was $25.8 \%$ [44••]. The main reason for conversion to laparotomy was obesity (approximately $60 \%$ of cases), and the conversion rate for morbidly obese women was $57 \%$ [44••]. Lack of surgical experience in using a laparoscopic technique for cancer treatment may be one key reason for such a high conversion rate; only $8 \%$ of surgical staging procedures for endometrial cancer were performed using laparoscopic surgery during the GOG LAP2 trial in the United States (19962005) [46•]. The results of eight RCTs comparing laparoscopy and laparotomy for surgical staging of endometrial

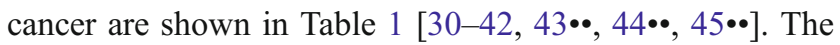
main reasons for conversion to laparotomy after initial assignment to laparoscopic surgery in these RCTs are shown in Table $2[30-42,43 \bullet \bullet, 44 \bullet \cdot, 45 \bullet \cdot$. Excluding the GOG LAP2 trial, the conversion rate in RCTs ranged from $0 \%$ to $10.8 \%$. In experienced surgeons' retrospective or prospective series, the conversion rate is approximately $5 \%[14,17$, $23,26,47]$. In series where experienced surgeons performed consecutive laparoscopic surgery for all patients with earlystage endometrial cancer, regardless of age, body mass index, uterine size, or history of prior surgery, the conversion rate was only $3-5 \%[46 \bullet, 48]$, and only $7 \%$ for morbidly obese patients [46•]. This indicates that laparoscopic surgery is feasible for the vast majority of patients with early-stage endometrial cancer; however, surgeon's experience in using the laparoscopic technique is critical to achieve good outcomes.

\section{Perioperative Outcomes and Complications of Laparoscopic Surgery}

Many retrospective studies [13-25], prospective nonrandomized studies [26-29], and meta-analyses [49•, $50-52,53 \cdot]$ published during the last decade have suggested that laparoscopic surgery has an improved outcomes profile in terms of estimated blood loss and transfusion requirements, recovery of bowel movement, postoperative hospital stay, and perioperative complications compared with laparotomy in the surgical management of endometrial cancer. These findings have been confirmed in recent RCTs comparing laparoscopy and laparotomy for surgical staging

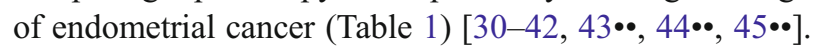

The following discussion of outcomes and complications of laparoscopic surgery compared with laparotomy is based on the results of the eight RCTs presented in Table 1. It can be seen that the operating time for laparoscopic surgery was similar to or slightly longer than that of laparotomy for surgical staging of endometrial cancer. However, operating time depended on the surgeon's experience with laparoscopic surgery. Estimated blood loss was significantly less for laparoscopic surgery in all RCTs, and transfusion requirement also was less frequent for laparoscopic surgery in most studies. The time interval to the recovery of bowel movement was reported in only one RCT, and it was significantly shorter in the laparoscopic surgery group. Postoperative hospital stay was significantly shorter for the laparoscopic surgery group in all RCTs. These results demonstrate the overall faster recovery of patients who undergo laparoscopic surgery compared with laparotomy. Other studies have reported less need for pain medication and quicker resumption of daily activities in patients who undergo laparoscopic surgery [42]. Intraoperative complication rates were similar between laparoscopic surgery and laparotomy in all RCTs, but postoperative complication rates were lower for the laparoscopic surgery group in most studies. The number of lymph nodes retrieved was similar between laparoscopic surgery and laparotomy in most studies. Therefore, laparoscopic surgery for surgical staging of endometrial cancer is associated with less blood loss and transfusion, faster recovery of bowel movement, less use of pain medication and quicker resumption of daily activities, shorter postoperative hospital stay, and less frequent postoperative complications compared with laparotomy. Operating time of laparoscopic surgery is similar to or slightly longer than that of laparotomy.

\section{Quality of Life after Laparoscopic Surgery}

Only four RCTs have reported quality of life (QOL) data for patients undergoing either laparoscopic or laparotomy [36, $37,39,42,43 \cdot 0]$. Zullo et al. performed QOL assessments at baseline, at 1, 2, and 6 months, and then annually for 7 years after surgery $[36,37]$. Laparoscopic surgery was associated with a significantly better QOL for the first 3 years after surgery, after which time no difference was noted.

Kornblith et al. reported quality of life (QOL) data for the first 802 patients of the GOG LAP2 study [43 •*]. Assessments were performed at baseline, at 1,3, and 6 weeks, and 6 months after surgery. Laparoscopic surgery was associated with significantly higher Functional Assessment of Cancer Therapy-General (FACT-G) scores, better physical 
Table 1 Results of randomized, controlled trials comparing laparoscopy and laparotomy for surgical staging of endometrial cancer

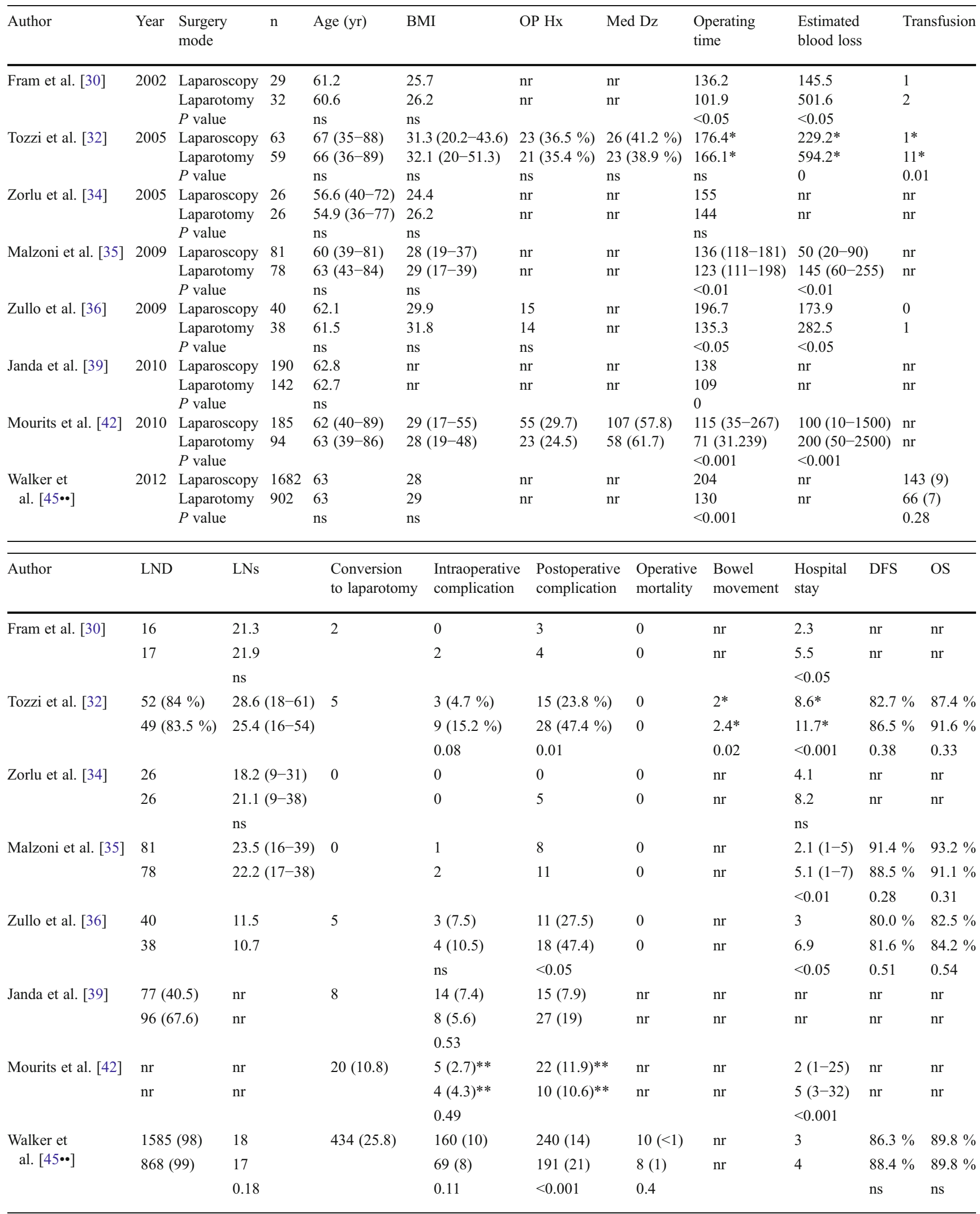

*Data were reported only in preliminary report

**Major complications 
Table 2 Cases that were convereted to laparotomy after assinged to laparoscopic surgery in randomized, controlled trials

\begin{tabular}{|c|c|c|c|c|}
\hline Author & Year & $\begin{array}{l}\text { Cases in } \\
\text { laparoscopy } \\
\text { group, } n\end{array}$ & $\begin{array}{l}\text { Converted cases, } \\
\mathrm{n}(\%)\end{array}$ & Reasons of conversion \\
\hline Fram et al. [30] & 2002 & 29 & $2(6.9)$ & $\begin{array}{l}\text { 1-improper bowel preparation } \\
\text { 1-thick omental adhesion }\end{array}$ \\
\hline Tozzi et al. [32] & 2005 & 63 & $5(7.9)$ & $\begin{array}{l}\text { 4-intraperitoneal disease } \\
\text { 1-small bowel injury during adheisolysis }\end{array}$ \\
\hline Zorlu et al. [34] & 2005 & 26 & 0 & - \\
\hline Malzoni et al. [35] & 2009 & 81 & 0 & - \\
\hline Zullo et al. [36] & 2009 & 40 & $5(12.5)$ & $\begin{array}{l}\text { 3-anesthesiologist indication for the } \\
\text { impossibility to maintain a } \\
\text { Trendelenburg's position during } \\
\text { surgical internvention } \\
\text { 1-extrauterine spread } \\
\text { 1-severe adhesion }\end{array}$ \\
\hline Obermair et al. [40] & 2012 & 404 & $24(5.9)$ & $\begin{array}{l}\text { 15-anatomical reasons that prevneted } \\
\text { completion of TLH } \\
\text { 7-intraoperative complication } \\
\text { 2-technical reasons }\end{array}$ \\
\hline Mourits et al. [42] & 2010 & 185 & $20(10.8)$ & $\begin{array}{l}\text { 9-inadequate exposure } \\
\text { 9-uterus too large } \\
\text { 1-bleeding } \\
\text { 2-technical problems } \\
\text { 5-obesity or anaesthetic complications } \\
\text { to obesity } \\
\text { 3-additional pathology } \\
\text { 1-other reason } \\
\text { Some patients had more than one reason } \\
\text { for conversion }\end{array}$ \\
\hline Walker et al. $[45 \bullet \bullet]$ & 2012 & 1682 & $434(25.8)$ & $\begin{array}{l}246(56.7) \text { - poor exposure } \\
69(43.1) \text {-cancer requiring laparotomy } \\
\text { for resection } \\
49(11.3) \text { - excessive bleeding } \\
10(2.3) \text { - equiment failure } \\
70(16.1) \text { - other cuase }\end{array}$ \\
\hline
\end{tabular}

functioning, better body image, less pain (including its effect on QOL), and an earlier resumption of normal activities and return to work at 6 weeks after surgery compared with laparotomic surgery. However, the difference in body image and return to work between laparoscopic and laparotomic surgery groups was modest at 6 weeks after surgery, and differences in QOL parameters were not significant at 6 months after surgery except for body image where laparoscopic surgery showed a significant benefit.

Janda et al. compared the QOL results of 361 patients undergoing either laparoscopy or laparotomy for stage I endometrial cancer [39]. QOL assessments were performed at baseline, at 1 and 4 weeks (early), and 3 and 6 months (late) after surgery. Laparoscopic surgery was associated with a significantly greater improvement in QOL from baseline compared with that of laparotomic surgery in all subscales of FACT-G except emotional and social well being in the early phase of recovery. Improvement in QOL up to 6 months after surgery continued to favor laparoscopic surgery, except for the emotional and social well being subscale of FACT-G and the visual analogue scale of the EuroQOL five dimensions (EuroQOL-VAS).

Mourits et al. also compared QOL results between laparoscopy and laparotomy as a secondary outcome of their study [42]. Assessments were performed at baseline, and at 6 weeks, 3 months, and 6 months after surgery. The response rate from the 283 study participants to the QOL questionnaire was $90.1 \%$. Laparoscopic surgery was associated with a significantly higher physical functioning subscale of the SF-36 at 6 weeks and a significantly higher rolephysical subscale at 3 months after surgery. However, laparoscopic surgery was associated with a significantly lower 
vitality subscale of the mental dimension at 3 months after surgery. There was no difference in other subscales between the two surgery groups.

These RCTs demonstrate that laparoscopic surgery is associated with an improved QOL compared with laparotomy after surgical staging for endometrial cancer, especially in the early phase of recovery. This benefit is, however, subdued in the late phase of recovery.

\section{Survival Outcomes After Laparoscopic Surgery}

There is no evidence that laparoscopic surgery compromises the survival of patients with endometrial cancer. Retrospective [13-25] or prospective, nonrandomized studies [26-29] have shown comparable survival outcomes for laparoscopic surgery and laparotomy. Four RCTs reported the long-term survival outcomes after laparoscopic surgery compared with laparotomy in patients with endometrial cancer (Table 1) $[33,35,36,45 \cdot \bullet]$. Laparoscopic surgery had similar survival outcomes compared with laparotomy in these RCTs. The GOG LAP2 trial was designed to confirm the noninferiority of recurrence-free interval, defined as a hazard ratio of 1.4, for laparoscopy relative to laparotomy with sufficient statistical power $[45 \cdot \bullet]$. This trial confirmed the equivalence of survival outcomes between laparoscopy and laparotomy for surgical management of endometrial cancer. The estimated 5-year recurrence rate was $13.68 \%$ for the laparoscopy group and $11.61 \%$ for the laparotomy group. The estimated 5 -year overall survival was $89.8 \%$ for both surgery groups. The pattern of recurrence was not different between the two groups. Trocar site recurrence occurred in only 4 of 1,696 patients $(0.24 \%)$ in the laparoscopy group. Because three of the four patients with trocar site recurrence had stage III-IV disease, the risk of trocar site recurrence after laparoscopic surgery in patients with stage I-II disease appears negligible. It can be concluded that laparoscopic surgery has equivalent survival outcomes compared with laparotomy after stating operation of endometrial cancer.

\section{Conclusions}

Surgical management is the main stay for the treatment of endometrial cancer. Surgical staging through laparotomy has been the "gold standard" surgical management for endometrial cancer. However, with recent advances in laparoscopic surgical techniques and instruments, all surgical procedures for the treatment of endometrial cancer can be performed using laparoscopy, and the use of laparoscopic surgery for the surgical management of endometrial cancer is continuously increasing. Current literature shows that laparoscopic surgery is the preferred alternative to laparotomic surgery for the surgical management of endometrial cancer. Laparoscopic surgery is feasible in the vast majority of patients with endometrial cancer if the surgery is performed by an experienced surgeon. Laparoscopic surgery is associated with favorable operative outcomes, including less blood loss and need for transfusion, less use of pain medication, faster recovery of bowel movement, shorter postoperative hospital stay, less frequent perioperative complications, earlier return to work, and faster resumption of daily activities. The lymph node yield is similar between laparoscopic surgery and laparotomic surgery. The QOL of patients in the early phase of recovery after surgery is significantly improved in patients who undergo laparoscopic surgery. The disease-free and overall survival rates after either laparoscopic or laparotomic surgery are comparable. Surgeon's training and experience are important factors in achieving optimal outcomes when using a laparoscopic approach.

Disclosures No potential conflicts of interest relevant to this article were reported.

\section{References}

Papers of particular interest, published recently, have been highlighted as:

- Of importance

•- Of major importance

1. Parkin DM, Bray F, Ferlay J, Pisani P. Global cancer statistics, 2002. CA Cancer J Clin. 2005;55(2):74-108.

2. Ferlay J, Shin HR, Bray F, Forman D, Mathers C, Parkin DM. Estimates of worldwide burden of cancer in 2008: GLOBOCAN 2008. Int J Cancer. 2010;127(12):2893-917.

3. Bray F, Loos AH, Oostindier M, Weiderpass E. Geographic and temporal variations in cancer of the corpus uteri: incidence and mortality in pre- and postmenopausal women in Europe. Int $\mathbf{J}$ Cancer. 2005;117(1):123-31.

4. Jemal A, Siegel R, Xu J, Ward E. Cancer statistics, 2010. CA Cancer J Clin. 2010;60(5):277-300.

5. Creasman WT, Odicino F, Maisonneuve P, Beller U, Benedet JL, Heintz AP, et al. Carcinoma of the corpus uteri. Int J Gynaecol Obstet. 2003;83 Suppl 1:79-118.

6. Jeong NH, Lee JM, Lee SK. Current status in the management of uterine corpus cancer in Korea. J Gynecol Oncol. 2010;21 (3):151-62.

7. Jung KW, Park S, Won YJ, Kong HJ, Lee JY, Park EC, et al. Prediction of cancer incidence and mortality in Korea, 2011. Cancer Res Treat. 2011;43(1):12-8.

8. Ushijima K. Current status of gynecologic cancer in Japan. J Gynecol Oncol. 2009;20(2):67-71.

9. Suh DH, Kim K, Kim JW. Major clinical research advances in gynecologic cancer in 2011. J Gynecol Oncol. 2012;23(1):53-64.

10. Sorosky JI. Endometrial cancer. Obstet Gynecol. 2008;111(2 Pt 1):436-47. 
11. Johnson N, Barlow D, Lethaby A, Tavender E, Curr E, Garry R. Surgical approach to hysterectomy for benign gynaecological disease. The Cochrane Database of Systematic Reviews 2005, Issue 2. Art. No.: CD003677. doi:10.1002/14651858.CD003677.pub3

12. Childers JM, Brzechffa PR, Hatch KD, Surwit EA. Laparoscopically assisted surgical staging (LASS) of endometrial cancer. Gynecol Oncol. 1993;51(1):33-8.

13. Nezhat F, Yadav J, Rahaman J, Gretz H, Cohen C. Analysis of survival after laparoscopic management of endometrial cancer. $\mathrm{J}$ Minim Invasive Gynecol. 2008;15(2):181-7.

14. Cho YH, Kim DY, Kim JH, Kim YM, Kim YT, Nam JH. Laparoscopic management of early uterine cancer: 10-year experience in Asan Medical Center. Gynecol Oncol. 2007;106(3):585-90.

15. Gil-Moreno A, Diaz-Feijoo B, Morchon S, Xercavins J. Analysis of survival after laparoscopic-assisted vaginal hysterectomy compared with the conventional abdominal approach for early-stage endometrial carcinoma: a review of the literature. J Minim Invasive Gynecol. 2006;13(1):26-35.

16. Sobiczewski P, Bidzinski M, Derlatka P, Danska-Bidzinska A, Gmyrek J, Panek G. Comparison of the results of surgical treatment using laparoscopy and laparotomy in patients with endometrial cancer. Int J Gynecol Cancer. 2005;15(5):946-51.

17. Kim DY, Kim MK, Kim JH, Suh DS, Kim YM, Kim YT, et al. Laparoscopic-assisted vaginal hysterectomy versus abdominal hysterectomy in patients with stage I and II endometrial cancer. Int J Gynecol Cancer. 2005;15(5):932-7.

18. O'Hanlan KA, Huang GS, Garnier AC, Dibble SL, Reuland ML, Lopez L, et al. Total laparoscopic hysterectomy versus total abdominal hysterectomy: cohort review of patients with uterine neoplasia. JSLS. 2005;9(3):277-86.

19. Zapico A, Fuentes P, Grassa A, Arnanz F, Otazua J, Cortes-Prieto J. Laparoscopic-assisted vaginal hysterectomy versus abdominal hysterectomy in stages I and II endometrial cancer. Operating data, follow up and survival. Gynecol Oncol. 2005;98(2):222-7.

20. Obermair A, Manolitsas TP, Leung Y, Hammond IG, McCartney AJ. Total laparoscopic hysterectomy versus total abdominal hysterectomy for obese women with endometrial cancer. Int J Gynecol Cancer. 2005;15(2):319-24.

21. Magrina JF, Weaver AL. Laparoscopic treatment of endometrial cancer: five-year recurrence and survival rates. Eur J Gynaecol Oncol. 2004;25(4):439-41.

22. Obermair A, Manolitsas TP, Leung Y, Hammond IG, McCartney AJ. Total laparoscopic hysterectomy for endometrial cancer: patterns of recurrence and survival. Gynecol Oncol. 2004; 92(3):789-93.

23. Eltabbakh GH. Analysis of survival after laparoscopy in women with endometrial carcinoma. Cancer. 2002;95(9):1894-901.

24. Scribner Jr DR, Walker JL, Johnson GA, McMeekin SD, Gold MA, Mannel RS. Surgical management of early-stage endometrial cancer in the elderly: is laparoscopy feasible? Gynecol Oncol. 2001;83(3):563-8.

25. Scribner Jr DR, Mannel RS, Walker JL, Johnson GA. Cost analysis of laparoscopy versus laparotomy for early endometrial cancer. Gynecol Oncol. 1999;75(3):460-3.

26. Kalogiannidis I, Lambrechts S, Amant F, Neven P, Van Gorp T, Vergote I. Laparoscopy-assisted vaginal hysterectomy compared with abdominal hysterectomy in clinical stage I endometrial cancer: safety, recurrence, and long-term outcome. Am J Obstet Gynecol. 2007;196(3):248 e1-8.

27. Volpi E, Ferrero A, Jacomuzzi ME, Carus AP, Fuso L, Martra F, et al. Laparoscopic treatment of endometrial cancer: feasibility and results. Eur J Obstet Gynecol Reprod Biol. 2006;124(2):232-6.

28. Seracchioli R, Venturoli S, Ceccarin M, Cantarelli M, Ceccaroni $\mathrm{M}$, Pignotti E, et al. Is total laparoscopic surgery for endometrial carcinoma at risk of local recurrence? A long-term survival. Anticancer Res. 2005;25(3c):2423-8.
29. Holub Z. The role of laparoscopy in the surgical treatment of endometrial cancer. Clin Exp Obstet Gynecol. 2003;30(1):7-12.

30. Fram KM. Laparoscopically assisted vaginal hysterectomy versus abdominal hysterectomy in stage I endometrial cancer. Int $\mathrm{J}$ Gynecol Cancer. 2002;12(1):57-61.

31. Malur S, Possover M, Michels W, Schneider A. Laparoscopicassisted vaginal versus abdominal surgery in patients with endometrial cancer - a prospective randomized trial. Gynecol Oncol. 2001;80(2):239-44.

32. Tozzi R, Malur S, Koehler C, Schneider A. Analysis of morbidity in patients with endometrial cancer: is there a commitment to offer laparoscopy? Gynecol Oncol. 2005;97(1):4-9.

33. Tozzi R, Malur S, Koehler C, Schneider A. Laparoscopy versus laparotomy in endometrial cancer: first analysis of survival of a randomized prospective study. J Minim Invasive Gynecol. 2005;12 (2):130-6.

34. Zorlu CG, Simsek T, Ari ES. Laparoscopy or laparotomy for the management of endometrial cancer. JSLS. 2005;9(4):442-6.

35. Malzoni M, Tinelli R, Cosentino F, Perone C, Rasile M, Iuzzolino D, et al. Total laparoscopic hysterectomy versus abdominal hysterectomy with lymphadenectomy for early-stage endometrial cancer: a prospective randomized study. Gynecol Oncol. 2009;112(1):126-33.

36. Zullo F, Palomba S, Falbo A, Russo T, Mocciaro R, Tartaglia E, et al. Laparoscopic surgery vs laparotomy for early stage endometrial cancer: long-term data of a randomized controlled trial. Am J Obstet Gynecol. 2009;200(3):296 e1-9.

37. Zullo F, Palomba S, Russo T, Falbo A, Costantino M, Tolino A, et al. A prospective randomized comparison between laparoscopic and laparotomic approaches in women with early stage endometrial cancer: a focus on the quality of life. Am J Obstet Gynecol. 2005; 193(4):1344-52.

38. Janda M, Gebski V, Forder P, Jackson D, Williams G, Obermair A. Total laparoscopic versus open surgery for stage 1 endometrial cancer: the LACE randomized controlled trial. Contemp Clin Trials. 2006;27(4):353-63.

39. Janda M, Gebski V, Brand A, Hogg R, Jobling TW, Land R, et al. Quality of life after total laparoscopic hysterectomy versus total abdominal hysterectomy for stage I endometrial cancer (LACE): a randomised trial. Lancet Oncol. 2010;11(8):772-80.

40. Obermair A, Janda M, Baker J, Kondalsamy-Chennakesavan S, Brand A, Hogg R, et al. Improved surgical safety after laparoscopic compared to open surgery for apparent early stage endometrial cancer: results from a randomised controlled trial. Eur J Cancer. 2012;48(8):1147-53.

41. Bijen CB, Briet JM, de Bock GH, Arts HJ, Bergsma-Kadijk JA, Mourits MJ. Total laparoscopic hysterectomy versus abdominal hysterectomy in the treatment of patients with early stage endometrial cancer: a randomized multi center study. BMC Cancer. 2009;9:23.

42. Mourits MJ, Bijen CB, Arts HJ, ter Brugge HG, van der Sijde R, Paulsen L, et al. Safety of laparoscopy versus laparotomy in earlystage endometrial cancer: a randomised trial. Lancet Oncol. 2010;11(8):763-71.

43. • Kornblith AB, Huang HQ, Walker JL, Spirtos NM, Rotmensch J, Cella D. Quality of life of patients with endometrial cancer undergoing laparoscopic international federation of gynecology and obstetrics staging compared with laparotomy: a Gynecologic Oncology Group study. J Clin Oncol. 2009;27(32):5337-42. This study is the largest, randomized, conrolled trial comparing laparoscopy and laparotomy for surgical staging of early-stage endoemtrial cancer. Quality of life of pateints was reported.

44. •- Walker JL, Piedmonte MR, Spirtos NM, Eisenkop SM, Schlaerth JB, Mannel RS, et al. Laparoscopy compared with laparotomy for comprehensive surgical staging of uterine cancer: Gynecologic Oncology Group Study LAP2. J Clin Oncol. 2009;27(32):5331-6. This study is the largest, randomized, conrolled trial comparing laparoscopy and laparotomy for 
surgical staging of early-stage endoemtrial cancer. Surgical outcome of pateints was reported.

45. .. Walker JL, Piedmonte MR, Spirtos NM, Eisenkop SM, Schlaerth JB, Mannel RS, et al. Recurrence and survival after random assignment to laparoscopy versus laparotomy for comprehensive surgical staging of uterine cancer: Gynecologic Oncology Group LAP2 Study. J Clin Oncol. 2012;30(7):695-700. This study is the largest, randomized, conrolled trial comparing laparoscopy and laparotomy for surgical staging of early-stage endoemtrial cancer. Survival outcome of pateints was reported in this study.

46. - Fanning J, Hossler C. Laparoscopic conversion rate for uterine cancer surgical staging. Obstet Gynecol. 2010;116(6):1354-7. This study reports the laparoscopic conversion rate for survival staging of early-stage endometrial cancer when the surgery is prefomred consecutively by the experienced surgery regardless of age, body mass index, uterine size, or history of prior surgery.

47. Barakat RR, Lev G, Hummer AJ, Sonoda Y, Chi DS, Alektiar KM, et al. Twelve-year experience in the management of endometrial cancer: a change in surgical and postoperative radiation approaches. Gynecol Oncol. 2007;105(1):150-6.

48. Eisenkop SM. Total laparoscopic hysterectomy with pelvic/aortic lymph node dissection for endometrial cancer - a consecutive series without case selection and comparison to laparotomy. Gynecol Oncol. 2010;117(2):216-23.
49. - Galaal K, Bryant A, Fisher AD, Al-Khaduri M, Kew F, Lopes AD. Laparoscopy versus laparotomy for the management of early stage endometrial cancer. Cochrane Database Syst Rev. 2012;9: CD006655. This article is a comprehensive review and metaalaysis of eight randomized, controlled trials comparing laproscopy and laparotomy for surgical stagiong of early-stage endometrial cancer that were ever reported.

50. Ju W, Myung SK, Kim Y, Choi HJ, Kim SC. Comparison of laparoscopy and laparotomy for management of endometrial carcinoma: a meta-analysis. Int J Gynecol Cancer. 2009;19(3):400-6.

51. Palomba S, Falbo A, Mocciaro R, Russo T, Zullo F. Laparoscopic treatment for endometrial cancer: a meta-analysis of randomized controlled trials (RCTs). Gynecol Oncol. 2009;112(2):415-21.

52. Lin F, Zhang QJ, Zheng FY, Zhao HQ, Zeng QQ, Zheng MH, et al. Laparoscopically assisted versus open surgery for endometrial cancer - a meta-analysis of randomized controlled trials. Int $\mathbf{J}$ Gynecol Cancer. 2008;18(6):1315-25.

53. - Zullo F, Falbo A, Palomba S. Safety of laparoscopy vs laparotomy in the surgical staging of endometrial cancer: a systematic review and metaanalysis of randomized controlled trials. Am J Obstet Gynecol. 2012;207(2):94-100. This article is a comprehensive review and meta-alaysis of eight randomized, controlled trials comparing laproscopy and laparotomy for surgical stagiong of early-stage endometrial cancer that were ever reported. 